\title{
№ 90
}

A NOVA METODOLOGIA DE REAJUSTE DOS PLANOS DE SAÚDE MEDIRÁ OS CUSTOS, OS PREÇOS E A EFICIÊNCIA DAS OPERADORAS?

\section{Disoc}

Diretoria de Estudos e Políticas Sociais

\footnotetext{
Outubro de 2020
}

Eduardo Pedral Sampaio Fiuza Alexandre Marinho Carlos Octávio Ocké-Reis 



\section{Nota Técnica}

A NOVA METODOLOGIA DE REAJUSTE DOS PLANOS DE SAÚDE MEDIRÁ OS CUSTOS, OS PREÇOS E A EFICIÊNCIA DAS OPERADORAS?

Disoc

Diretoria de Estudos e Políticas Sociais
Eduardo Pedral Sampaio Fiuza Alexandre Marinho Carlos Octávio Ocké-Reis 


\section{Governo Federal}

Ministério da Economia

Ministro Paulo Guedes

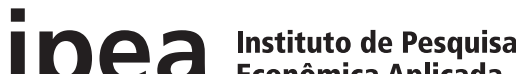

Fundação pública vinculada ao Ministério da Economia o Ipea fornece suporte técnico e institucional às ações governamentais - possibilitando a formulação de inúmeras políticas públicas e programas de desenvolvimento brasileiros - e disponibiliza, para a sociedade, pesquisas e estudos realizados por seus técnicos.

\section{Presidente}

Carlos von Doellinger

Diretor de Desenvolvimento Institucional Manoel Rodrigues Junior

Diretora de Estudos e Políticas do Estado,

das Instituições e da Democracia

Flávia de Holanda Schmidt

\section{Diretor de Estudos e Políticas}

\section{Macroeconômicas}

José Ronaldo de Castro Souza Júnior

Diretor de Estudos e Políticas Regionais,

Urbanas e Ambientais

Nilo Luiz Saccaro Júnior

Diretor de Estudos e Políticas Setoriais de Inovação

e Infraestrutura

André Tortato Rauen

Diretora de Estudos e Políticas Sociais

Lenita Maria Turchi

Diretor de Estudos e Relações Econômicas

e Políticas Internacionais

Ivan Tiago Machado Oliveira

\section{Assessora-chefe de Imprensa}

e Comunicação

Mylena Fiori

Ouvidoria: http://www.ipea.gov.br/ouvidoria

URL: http://www.ipea.gov.br 


\section{Nota Técnica}

A NOVA METODOLOGIA DE REAJUSTE DOS PLANOS DE SAÚDE MEDIRÁ OS CUSTOS, OS

№ 90 PREÇOS E A EFICIÊNCIA DAS OPERADORAS?

Disoc

Diretoria de Estudos e Políticas Sociais

Outubro de 2020
Eduardo Pedral Sampaio Fiuza Alexandre Marinho Carlos Octávio Ocké-Reis

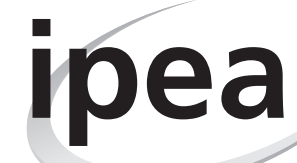




\section{EQUIPE TÉCNICA}

\section{Eduardo Pedral Sampaio Fiuza}

Técnico de planejamento e pesquisa na Diretoria de Estudos e Políticas Setoriais de Inovação e Infraestrutura (Diset) do Ipea. E-mail:<eduardo.fiuza@ ipea.gov.br>.

\section{Alexandre Marinho}

Técnico de planejamento e pesquisa na Diset/lpea.E-mail: <alexandre.marinho@ipea.gov.br>.

\section{Carlos Octávio Ocké-Reis}

Técnico de planejamento e pesquisa na Diretoria de Estudos e Políticas Sociais (Disoc) do Ipea. E-mail: <carlos.ocke@ipea.gov.br>.

As publicações do Ipea estão disponíveis para download gratuito nos formatos PDF (todas) e EPUB (livros e periódicos). Acesse: <http://www.ipea.gov.br/ portal/publicacoes>.

As opiniões emitidas nesta publicação são de exclusiva e inteira responsabilidade dos autores, não exprimindo, necessariamente, o ponto de vista do Instituto de Pesquisa Econômica Aplicada ou do Ministério da Economia.

É permitida a reprodução deste texto e dos dados nele contidos, desde que citada a fonte. Reproduções para fins comerciais são proibidas. 


\section{SUMÁRIO}

1 INTRODUÇÃO..

7

2 RETROSPECTIVA INSTITUCIONAL_....................................................................................................................................................................... 7

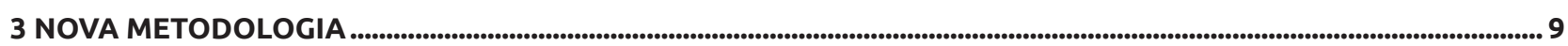

4 UMA QUEBRA DE PARADIGMA É NECESSÁRIA? ................................................................................................................................... 15

5 CONSIDERAÇÕES FINAIS.............................................................................................................................................................................................. 16

REFERÊNCIAS _........................................................................................................................................................................................................ 17

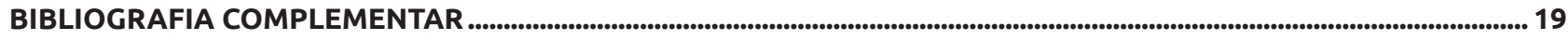

APÊNDICE A

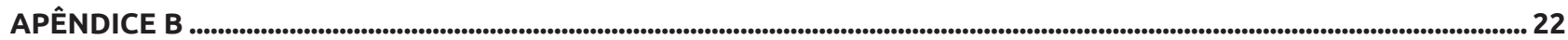





\section{INTRODUÇÃO}

A Agência Nacional de Saúde Suplementar (ANS) aprovou uma nova metodologia de cálculo do reajuste dos planos de saúde individual e familiar em 19 de dezembro de 2018. A regulação dos preços é necessária em vista das várias falhas de mercado presentes nesse setor: demanda induzida, risco moral, externalidades - por exemplo, no caso do tratamento de doenças infectocontagiosas -, entre outras (Cutler e Zeckhauser, 2000; Ocké-Reis e Cardoso, 2006). Também na medicina se verifica a chamada "doença dos custos" (Baumol, 1993, p. 19), que conduz a uma apreciação histórica dos serviços de saúde em relação a outros bens e serviços de consumo. ${ }^{1}$

Nosso objetivo é compreender os pressupostos teóricos dessa metodologia, tendo em mente o exame da sua capacidade de medir a evolução dos custos e preços desse segmento, bem como de mensurar a eficiência das operadoras em funcionamento no mercado de planos de saúde brasileiro.

Cabe assinalar, a agência reguladora não fez aparentemente qualquer avaliação de impacto dessa nova regra ${ }^{2}-$ por exemplo - a partir dos dados de desempenho das operadoras observados no passado, o que nos deixou reticentes para construir cenários empíricos, a partir da utilização dos microdados da ANS. De fato, como os microdados das operadoras não estão disponíveis para nós, nenhum exercício empírico foi realizado nesta nota técnica (NT).

Nessa linha, dividimos este trabalho em quatro seções, além desta introdução. Na seção 2, faremos uma breve retrospectiva das alternativas regulatórias avaliadas pela ANS. Na seção 3, questionamos algumas dimensões técnicas assumidas pela nova metodologia, em especial seu modelo de regulação por desempenho e o fator de ganhos de eficiência (FGE) - equivalente ao chamado fator X dos modelos de regulação por teto de preços (price cap). ${ }^{3} \mathrm{Na}$ seção 4, além de apontar lacunas presentes no debate, sugerimos uma abordagem mais ousada para se regular o setor de saúde suplementar, que requereria uma quebra de paradigma e uma conciliação dessa regulação com a do próprio Sistema Único de Saúde (SUS). Na seção 5, resumiremos as principais conclusões deste trabalho.

\section{RETROSPECTIVA INSTITUCIONAL}

Apesar de meritório, o conjunto de propostas regulatórias examinado ao longo do tempo pela burocracia da ANS não é o objeto central deste estudo e, sim, a proposta hoje em vigor. Desse modo, optamos por apresentar tão somente uma descrição sucinta das características de tais propostas nesta seção.

A discussão sobre a adoção de modelos de reajustes de preços de planos de saúde, incorporando medidas de produtividade ou de eficiência, não é nova, e ocorre, pelo menos, desde agosto de 2009 com a criação da Câmara Técnica Novo Modelo de Reajuste. O processo foi deflagrado com a elaboração da NT nํ 1.587/2009, na qual consta a seguinte declaração: ${ }^{4}$

Por solicitação da diretoria será desenvolvido um projeto visando a discussão da atual sistemática de reajuste dos planos individuais pós-regulamentados com vistas à construção de um possível novo modelo para setor (...). O novo modelo deverá refletir com maior eficiência a variação anual dos custos do setor de saúde suplementar, contemplando ainda os esforços das operadoras de planos de assistência à saúde para a melhoria da produtividade/qualidade/eficiência em suas atividades. Solicitou-se igualmente que o novo modelo capture eventuais variações geradas por eventos exógenos nos custos dos planos individuais (...). Destaca que o modelo em estudo seria baseado no price cap (preço-teto), sendo representado pela fórmula $\mathrm{R}^{\mathrm{k}}=\mathrm{I}_{\mathrm{t}}-\mathrm{X}_{\mathrm{t}}^{\mathrm{k}}+\mathrm{Y}^{\mathrm{k}}{ }_{\mathrm{t}}$, onde: $I_{t}=$ indicador setorial para todas as operadoras com planos individuais; $X^{k}{ }_{t}=$ indicador de eficiência para operadora $\mathrm{k}$ no ano $\mathrm{t} ; \mathrm{Y}_{\mathrm{t}}^{\mathrm{k}}=$ indicador ligado a eventos exógenos.

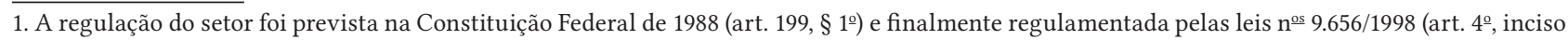
XVII) e 9.961/2000, que criam e regulamentam as competências da ANS (art. 4º, inciso XVII). E, como destacam Pietrobon, Prado e Caetano (2008), o modelo de regulação do setor de saúde suplementar brasileiro, diferentemente da maioria dos países - onde a regulação atua sobre as empresas do setor, suas condições de solvência e a competitividade do mercado -, optou por regular diretamente o produto oferecido, ou seja, a assistência à saúde. 2. Diferentemente de outras propostas preliminares que foram exibidas durante o processo de discussão da revisão das regras de reajuste. Ver, por exemplo, o documento de Andrade (2015).

3. Desenvolvido por Littlechild (1983), o regime de teto de preços foi largamente utilizado para a regulação de serviços de utilidade pública britânicos, tipicamente monopólios naturais, privatizados no governo Thatcher. Posteriormente o modelo foi copiado, eventualmente com adaptações, por diversas outras autoridades regulatórias ao redor do mundo. Seu conceito é bem simples: em vez de repassar aos consumidores em reajustes de preços toda a inflação passada (como era praxe nos idos da correção monetária brasileira durante os anos 1960 ao início da década de 1990), desconta-se dessa variação passada uma taxa de ganho de produtividade definida com antecedência pelo regulador - o chamado fator X -, induzindo, assim, a que o agente regulado persiga ganhos de eficiência superiores a essa taxa, pois ele se apropria da diferença entre o projetado e o efetivamente conquistado. Para uma melhor discussão do tema, sugerimos a leitura de Armstrong, Cowan e Vickers (1994) e Bernstein e Sappington (1999). O teto de preços substituiu, em larga escala, várias regulações pré-existentes baseadas na taxa de retorno sobre o capital, um regime que comprovadamente distorcia a alocação de fatores em favor do capital - o chamado efeito Averch-Johnson (Train, 1991).

4. Não nos foi possível recuperar essa NT no 1.587/2009 da Gerência-Geral Regulatória da Estrutura dos Produtos da Diretoria de Normas e Habilitação dos Produtos (GGREP/Dipro) da ANS. O regimento interno da Câmara Técnica Novo Modelo de Reajuste foi aprovado pela Diretoria Colegiada da ANS em 26 de maio de 2010 (a primeira sessão ocorreu em 1o de junho de 2010; a quinta e última reunião do seu grupo técnico ocorreu em 30 de dezembro de 2011).

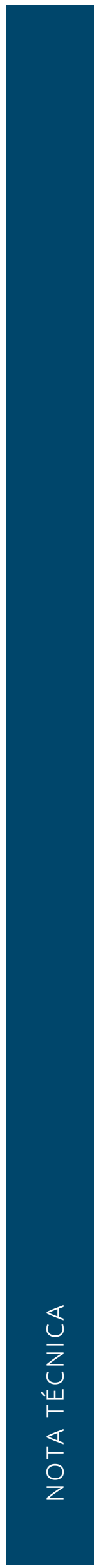


A câmara técnica se reuniu cinco vezes entre 2009 e 2011 e, de acordo com a NT no $1.180 / 2011$, contou com a participação de servidores e representantes de diversas instituições, entre as quais: Associação Médica Brasileira (AMB); Agência Nacional de Vigilância Sanitária (Anvisa); Conselho Federal de Medicina (CFM); Conselho Nacional de Saúde (CNS); Confederação das Santas Casas de Misericórdia, Hospitais e Entidades Filantrópicas (CMB); Departamentos de Proteção e Defesa do Consumidor e de Proteção e Defesa Econômica da Secretaria de Direito Econômico do Ministério da Justiça (DPDC/SDE/MJ e DPDE/SDE/MJ); Federação Brasileira de Hospitais (FBH); Federação Nacional de Saúde Suplementar (FenaSaúde); Fundação do Instituto de Pesquisas Contábeis, Atuariais e Financeiras (Fipecafi); Instituto Brasileiro de Defesa do Consumidor (Idec); Ipea; Ministério da Fazenda; Ministério da Saúde; Ministério da Previdência Social; Procon Municipal São José dos Campos; Procon São Paulo; Sindicato Nacional das Empresas de Medicina de Grupo (Sinamge); Associação Brasileira de Defesa do Consumidor (Proteste); União Nacional das Instituições de Autogestão em Saúde (Unidas); Confederação Nacional das Cooperativas Médicas (Unimed do Brasil); Sindicato Nacional das Empresas de Odontologia de Grupo (Sinog); e Sociedade Cooperativa de Serviços Odontológicos (Uniodonto).

Em 30 de dezembro de 2011, foi redigida a NT no 1.180/2011 com as alegações para a não adoção das medidas preconizadas pelo grupo técnico da referida câmara, encerrando, assim, as tentativas de adoção de um novo modelo de reajuste, sem que, no nosso conhecimento, alguma outra proposta tivesse sido efetivamente aventada de forma imediata.

As limitações que inviabilizaram a implementação de um novo modelo de reajuste foram:

1) Os índices de preços externos não foram considerados adequados porque não medem a variação de frequência de utilização dos procedimentos, que é um dos componentes da variação dos custos das operadoras.

2) As mudanças conceituais do Sistema de Informação de Produtos (SIP) impossibilitaram a construção de uma série histórica. Ademais, o SIP não segrega os dados da carteira individual de planos novos, que são o objeto da regulação de reajustes.

3) A regionalização do índice, baseada na média dos reajustes dos planos coletivos, é operacionalmente viável, mas a quebra do federalismo do reajuste poderia suscitar desequilíbrios na capacidade de pagamento dos beneficiários, particularmente no Nordeste.

4) O índice de variação do custo médico-hospitalar (VCMH), medido com base nos dados contábeis, apresentou grande amplitude entre dois períodos, impossibilitando a validação do método e aplicação dos percentuais apurados (ANS, 2011, folha 35).

Desse modo, então, foi encerrado o primeiro ciclo de tentativa de adoção de um modelo de reajuste do tipo price cap, com um componente de produtividade ou eficiência, baseado em métodos de fronteiras de eficiência econômica.

Motivada pela recente crise econômica, a ANS passou a se interessar novamente pelo cálculo de eficiência econômica das operadoras, que poderia ter sido objetivamente introduzido na metodologia de cálculo dos reajustes de preços a partir de 2017. A NT no 30/2018 apresenta a descrição de proposta de metodologia de cálculo do reajuste dos planos individuais de cobertura médico-hospitalar regulamentados pela Lei no 9.656/1998, após realização da audiência pública em 13 de novembro de 2018. Nesse contexto, a NT nº 30/2018 diz:

a conclusão foi que ponderar despesas assistenciais e não assistenciais na fórmula do reajuste, traria mais transparência e refletiria melhor os custos operacionais das operadoras. A nova alternativa é denominada value cap ponderado entre despesas assistenciais e não assistenciais (ANS, 2018b, seção 1).

Em particular, essa NT faz menção específica à elaboração, por iniciativa da ANS, de um modelo utilizando uma análise envoltória de dados (Data Envelopment Analysis - DEA), que é um método não paramétrico de cálculo de fronteira de eficiência econômica. Entretanto, o método não foi efetivamente adotado, sob a alegação de que "além de ser considerado complexo, o mesmo não atendia a finalidade de incentivar operadoras a atuarem como gestoras de assistência à saúde de seus beneficiários, uma vez que o único insumo eram as despesas administrativas” (ANS, 2018b, seção 5.1).

Segundo a própria NT no 30/2018, duas alternativas metodológicas foram posteriormente cotejadas, mas também descartadas. Pela sua importância, reproduzimos novamente seu conteúdo.

Entre 2017 e 2018, outras duas alternativas foram analisadas: a primeira foi a utilização do fator de produtividade da economia, calculado a partir da variação média em quatro anos do índice do PIB pela população ocupada. Houve críticas relacionadas ao caráter geral do índice e ao risco de impactos causados por outros setores da economia na sua mensuração. A segunda foi o cálculo de um fator de produtividade da saúde privada, baseado na publicação das contas satélites de saúde do IBGE. Contudo, por ser um indicador influenciado por atividades de prestação de serviços, entendeu-se que o conceito era incompatível com a produtividade de uma operadora de planos de assistência à saúde. Considerando as limitações conceituais das alternativas anteriormente estudadas, surge a proposição do fator de ganhos de eficiência - FGE (ANS, 2018b, seção 5.1). 
Pelo visto, a rejeição das alternativas precedentes pela ANS culminou na adoção de uma nova metodologia, que é o objeto deste trabalho.

\section{NOVA METODOLOGIA}

De acordo com a ANS, o novo Índice de Reajuste dos Planos Individuais (IRPI) combina a variação das despesas assistenciais (VDA) com o Índice de Preços ao Consumidor Amplo (IPCA) - expurgado o item plano de saúde. Assim, a VDA reflete as despesas assistenciais, ou seja, as despesas das operadoras com o atendimento dos usuários de planos individuais de saúde, enquanto o IPCA incide sobre as despesas não assistenciais (despesa administrativa, por exemplo). O índice não se baseia exclusivamente na VDA, embora se expresse em uma fórmula única, que reúne duas variações, de acordo com ANS (2019): despesas assistenciais (peso de 80\%) e não assistenciais (peso de 20\%) - de acordo com a proporção observada no próprio mercado nos últimos anos entre as despesas assistenciais e o conjunto das despesas administrativas, de comercialização e operacionais. Esse índice traz outras vantagens como a redução do tempo entre o período do cálculo e o período de aplicação do reajuste, além dos dados serem públicos e auditados, conferindo, em tese, maior transparência ao índice (ANS, 2018d). ${ }^{5}$

Cabe assinalar que o Índice de Variação das Despesas Assistenciais (IVDA) é, por sua vez, composto por três fatores: VDA; variação da receita por faixa etária (VFE), que deduz a parcela da receita das operadoras que já foi recomposta pelos reajustes por mudança de faixa etária; e o FGE, que é um suposto índice de eficiência, apurado a partir da VDA, que, hipoteticamente, transfere para os consumidores a eficiência média do setor e evita um modelo de repasse automático da variação das despesas médico-hospitalares (ANS, 2018c).

Essa composição é sintetizada pelas seguintes fórmulas:

$$
\text { IRPI }=80 \% * I V D A+20 \% * I P C A \operatorname{Exp} \text {, }
$$

em que IRPI = Índice Máximo de Reajuste dos Planos Individuais; IVDA = Índice de Valor das Despesas Assistenciais dos planos individuais médico-hospitalares com ou sem cobertura odontológica posteriores à Lei nº 9.656/1998; e IPCA Exp. = Índice de Preços ao Consumidor Amplo Expurgado do subitem plano de saúde.

O IVDA é obtido pela fórmula:

$$
\operatorname{IVDA}=((1+(\mathrm{VDA}-\mathrm{FGE})) /(1+\mathrm{VFE}))-1
$$

em que VDA = variação das despesas assistenciais dos planos individuais médico-hospitalares com ou sem cobertura odontológica posteriores à Lei no 9.656/1998; FGE = fator de ganhos de eficiência; e VFE = variação da receita faixa etária dos planos individuais médico-hospitalares com ou sem cobertura odontológica posteriores à Lei no $9.656 / 1998$.

A VDA é calculada da seguinte forma:

$$
V D A_{t a}=\left[\sum_{i=1}^{n} \frac{\left(\frac{D A_{i t a}}{B e n_{i t a}}\right)}{\left(\frac{D A_{\text {ita }}-1}{B e n_{\text {ita }}-1}\right)} x\left(\frac{B e n_{i t a}}{\text { Ben }_{\text {total ta }}}\right)\right]-1
$$

em que $i=$ operadora $i$; $t=$ último trimestre com dados disponíveis do Documento de Informações Periódicas das Operadoras de Planos de Assistência à Saúde (Diops/ANS) do ano de cálculo do reajuste; $a=$ ano de cálculo do IRPI; $D A=$ despesas assistenciais dos planos individuais de cobertura médico-hospitalar regulamentados pela Lei no 9.656/1998, acumuladas em doze meses até o trimestre $t$ do ano $a$ da operadora; Ben = média de beneficiários dos planos individuais de cobertura médico-hospitalar regulamentados pela Lei no 9.656/1998 da operadora; e Bentotal = média de beneficiários dos planos individuais de cobertura médico-hospitalar regulamentados pela Lei no 9.656/1998 no período de doze meses que antecede o cálculo do reajuste do mercado.

\subsection{Modelo de regulação por desempenho}

Desde 2001, a ANS estabeleceu um IRPI a partir da média dos aumentos dos planos coletivos dos últimos doze meses (exceto os planos com até cinquenta beneficiários ou os que não têm patrocinador). Essa metodologia, inspirada no modelo de regulação por desempenho (yardstick competition), procura reduzir custos e eliminar os excessos de assimetria de informação ao definir o teto de reajuste com base em um mercado específico de referência. 
Os reajustes estão circunscritos aos planos de assistência à saúde individual e familiar com contratos realizados a partir de 1999, assim como aos planos de autogestão não patrocinados e aos planos anteriores à Lei no 9.656/1998 não adaptados, cujas cláusulas contratuais não indiquem claramente o índice ou os critérios para fins de cálculo de reajuste. A rigor, tais reajustes não representam tabelamento do valor nominal dos planos individuais, mas apenas um percentual de reajuste para os contratos novos com mais de um ano; em outras palavras, conformam um teto fixado anualmente, que delimita a variação dos prêmios e as contraprestações pecuniárias. Dessa maneira, a partir de 2000 , passa a existir uma demarcação do teto de reajuste dos preços dos planos individuais novos e não um controle de preços stricto sensu. Em síntese, o preço mínimo de entrada só tem o seu piso regulado, mas não seu teto, para evitar, sobretudo, as práticas de preços predatórios (preço abaixo do custo para afastar concorrentes).

A antiga metodologia de cálculo do reajuste dos planos individuais da ANS era cercada de controvérsias: inspirada no modelo de regulação por desempenho, criou-se a expectativa de que a aplicação dessa metodologia fosse capaz de reduzir custos e assimetrias de informação, bem como estimular a eficiência econômica.

Havia, no entanto, limites nesse modelo como a possibilidade de formação de conluio entre as firmas para influenciar o resultado, bem como a dificuldade de acesso a informações relacionadas ao custo, resultante da competição entre os agentes econômicos. De fato, identifica-se um problema nessa metodologia: não são considerados os custos dos planos coletivos, mas, sim, o aumento percentual de seu preço (Brasil, 2018).

Além disso, imaginou-se que os consumidores dos planos coletivos - que não eram regulados - teriam capacidade de barganha para negociar os contratos com as operadoras e as administradoras de benefícios, mas, na prática, não foi isso que aconteceu. Observou-se, ao contrário, um aumento sistemático dos preços dos planos coletivos, que, embora não regulados, deveriam justamente servir de referência para o núcleo da política de reajuste de preços dos planos individual e familiar da ANS.

Posto isso, seria de fato o yardstick competition (YC) - que vigorou na $\mathrm{ANS}^{6}$ até 2018 - um modelo de regulação por desempenho?

Para respondermos isso, precisamos antes entender as diferentes definições do conceito de YC, uma das quais nos leva a uma necessidade ainda anterior, que é a de definir benchmarking. Segundo Bogetoft e Otto (2011, p. 1-2), o conceito de benchmarking pode ser definido da seguinte forma:

é a comparação sistemática de desempenho de uma firma contra outras firmas. De maneira mais geral, é a comparação de entidades produtivas. A ideia é que comparamos entidades que transformam o mesmo tipo de recursos no mesmo tipo de produtos e serviços. As entidades produtivas podem ser firmas, organizações, divisões, setores, projetos, unidades de tomada de decisão, ou indivíduos.

A comparação pode ser intraorganizacional - por exemplo, unidades de uma rede de fast food, ou filiais regionais de uma grande firma -, interorganizacional - o exemplo clássico é aquele do regulador que pretende introduzir eficiência de custos ou evitar o uso do poder monopolístico entre firmas com direitos de monopólio em diferentes territórios -, ou longitudinal - quando se compara o desempenho de uma ou mais firmas em períodos de tempo. Vê-se que o benchmarking não é a regulação em si, mas sim um passo importante para adotar um tipo de regulação, que promova a competição entre os agentes por resultados, conhecida como YC ou competição por padrão, que é usado em mercados em que tais agentes não têm incentivo a promover a eficiência produtiva, por exemplo, quando a competição é fraca ou ausente. O Netherlands Bureau for Economic Policy Analysis distingue três definições alternativas para YC (CPB, 2000, p. 15-16).

1) O "principal" recompensa os "agentes" de acordo com seu desempenho: a eficiência é comparada entre o conjunto dos agentes que oferecem produtos ou serviços similares, e suas receitas e lucros acabam dependendo do seu nível de desempenho (o resultado financeiro é o mecanismo que induz a competição entre tais agentes).

2) YC pode ser descrito como uma maneira de associar o resultado financeiro ao processo de benchmarking, isto é, a remuneração do agente depende de sua posição relativa aos demais.

3) YC é um tipo de torneio onde os agentes competem por custos mais baixos.

O YC ideal compara operadoras ou planos que não competem entre si. ${ }^{7}$ A nosso ver, o ponto mais importante a ser debatido é o fato de que o YC-ANS, em certo sentido, deturpou o próprio conceito de YC, ao aplicá-lo, não ao processo produtivo ou uso de insumos, mas, sim, ao resultado, o que contraria as definições mencionadas 
anteriormente. ${ }^{8}$ Em outras palavras, o que era aplicado pela ANS não pode ser considerado stricto sensu como um YC, pois: $i$ ) balizavam-se os preços de um segmento de planos (individuais) a partir de outro segmento de planos (coletivo), os quais, em tese, poderiam concorrer entre eles; e ii) a regra baseava-se em uma comparação de preços - e não de desempenho.

Em tese, as condições necessárias, mas não suficientes, para aplicação do YC são as descritas a seguir (CPB, 2000, p. 21-24).

1) Presença de falhas de mercado, o que acarretaria baixos incentivos para promover a redução de custos.

2) Comparabilidade entre os agentes econômicos para aferir o desempenho relativo de um em relação aos outros.

3) A informação privada dos agentes sobre seu desempenho: i) gera benefícios potenciais para propiciar os agentes a explorarem suas vantagens informacionais (pois eles auferem rendas de monopólio sobre essa informação) e ii) se a informação for correlacionada, a assimetria informacional pode ser usada para comparar agentes, sem que se tenha que revelar explicitamente a informação (o regulador explora a correlação para extrair com ela a tendência comum dos custos, isolando os efeitos individuais de cada firma).

4) Verificabilidade das informações: as informações podem ser auditadas e periciadas.

Um benchmark, no entanto, não deve ser confundido com o YC - como, de fato, não o foi pela ANS. Como salienta o CPB (2000), o benchmarking é apenas a primeira metade do YC. A segunda metade consiste na conexão, ou vinculação, das consequências financeiras aos resultados do benchmarking. Como não há consequências financeiras diretas associadas ao benchmarking, ele pode ser aplicado a um grupo de comparação mais amplo. Por exemplo, o benchmarking geralmente é feito internacionalmente, enquanto isso parece muito mais difícil para o YC. Por sua vez, o requisito de comparabilidade tem que ser cumprido para efetivar o benchmark. Contudo, nem a falha de mercado, nem o requisito de informação privada tem de ser cumprido para o benchmarking. Empresas privadas podem recorrer ao benchmarking para poder acompanhar ou competir mais fortemente com seus concorrentes (CPB, 2000).

\subsection{Regulação, desempenho e eficiência de planos de saúde}

Para se fazer um balizamento por desempenho econômico (benchmarking), uma alternativa seria aplicar algum método de avaliação comparativa de eficiência econômica (por exemplo, eficiência no sentido de Pareto-Koopmans). ${ }^{9}$ Os métodos mais utilizados são a DEA - método não paramétrico de programação matemática - e a análise de fronteiras estocásticas (stochastic frontier analysis - SFA) - método paramétrico (abordagem econométrica). ${ }^{10}$ Eles deveriam ser aplicados utilizando-se um conjunto de indicadores de desempenho (inputs e outputs) de todos os tipos de operadoras e planos, e não apenas as despesas assistenciais e/ou administrativas (Carrington, Coelli e Rao, 2011; Hashimoto, 2010). Essa comparação multidimensional de desempenho poderia balizar um padrão de medida (yardstick) individual para cada plano ou operadora (dependendo da granularidade dos dados disponíveis, isto é, do grau de desagregação da informação), tendo como base uma "cesta" de planos ou operadoras de diversos segmentos com uma defasagem temporal mínima.

Carrington, Coelli e Rao (2011) propõem um esquema para evitar a necessidade de movimentos bruscos na direção da fronteira de eficiência que poderiam implicar a quebra das empresas menos eficientes. Cada empresa deveria realizar um catching up de apenas $50 \%$ do seu hiato (gap) de eficiência técnica - isto é, precisaria reduzir apenas $50 \%$ de sua defasagem em relação à fronteira - em um período de cinco anos. Então, vamos supor uma empresa com eficiência de $50 \%$ (uma performance muito ruim). Ela teria um catching up de (1-0,5)/2=0,25 ou $25 \%$ em cinco anos. Isso representa uma taxa anualizada composta igual a $\sqrt[1 / 5]{1+0,25}=1,0456$, o que significa um catching up anual de 4,56\%. Então, o fator X será igual a $1,25 \%+4,56 \%=5,81 \%$. Ou seja, a empresa teria de reduzir seus custos em $5,81 \%$ ao ano. Supondo que os custos gerenciáveis sejam 10\% dos custos totais da empresa, os prêmios (anuidades cobradas) deveriam cair apenas $0,581 \%$ ao ano.

8. Se tentássemos encaixar o YC-ANS na definição 2 de YC mencionada, teríamos que aceitar o uso do termo benchmarking também para preços - que refletem condições de mercado e, portanto, excedem o que a firma é capaz de gerenciar. O mais coerente, no entanto, é usar-se o benchmarking para variáveis de desempenho dos agentes, variáveis estas que normalmente medem produtividade, custos e/ou qualidade entregue (do produto, serviço).

9. Em que consiste a eficiência no sentido de Pareto-Koopmans? Diz-se que "uma unidade produtiva é eficiente se um aumento em qualquer output requer a redução da quantidade de pelo menos um outro output, ou o aumento da quantidade de pelo menos um input; e se a redução de qualquer input requer, ou um aumento da quantidade de pelo menos um outro input para manter as quantidades de todos os outputs, ou a redução da quantidade de pelo menos um output. Um produtor tecnicamente ineficiente poderia produzir as mesmas quantidades de todos os outputs, utilizando menor quantidade de, pelo menos, um input, ou utilizar as mesmas quantidades de todos os inputs, para produzir mais de, pelo menos, um output" (Koopmans, 1951 apud Fried, Lovell e Schmidt, 2008, p. 20).

10. A DEA usa modelos de programação matemática para maximizar o quociente resultante da divisão dos outputs ponderados por pesos ótimos pelos inputs ponderados por pesos ótimos. Os quocientes gerados em cada unidade produtiva são comparados, gerando escores de eficiência e um ranking entre as unidades produtivas. Todo o desvio em relação ao melhor desempenho na amostra (benchmark) é tratado como ineficiência. A SFA utiliza modelos de regressão para medir o afastamento entre o nível de produção observado e o nível ótimo estimado por uma função de produção, escolhida previamente. Uma parte dos desvios é atribuída às aleatoriedades (erros aleatórios) e outra parte à ineficiência. Quanto menor o desvio que mede a ineficiência, maior será o escore de eficiência da unidade produtiva, de modo que um ranking entre as unidades também será gerado. Em ambos os métodos, as unidades avaliadas como plenamente eficientes formam um conjunto chamado de fronteira de eficiência. Para mais detalhes sobre DEA, ver Fernandes e Marinho (2018) e Bogetoft e Otto (2011). Para mais detalhes sobre SFA, ver Marinho, Cardoso e Almeida (2012) e Bogetoft e Otto (2011).

. 
Os inputs e outputs que são comumente utilizados em avaliações de eficiência, ou de produtividade, de planos e seguros de saúde estão listados na literatura internacional, como em Carrington, Coelli e Rao (2008; 2011), que utilizam DEA, e Yuda (2016) que utiliza SFA. Isso também ocorre na literatura nacional, nos trabalhos que usam DEA, como Andrade (2015), Hashimoto (2010) e Alves (2009). Vale notar que apenas um entre os trabalhos citados utiliza SFA, o que denotaria uma certa preferência de avaliadores de planos de saúde pela DEA diante da SFA. Esse fato talvez pode ser explicado pela capacidade de a primeira análise trabalhar melhor do que a segunda em pequenas amostras, que são de ocorrência comum em mercados pouco concorrenciais. ${ }^{11}$

Entre os inputs, temos as seguintes categorias de despesas: total; administrativas; médicas ou assistenciais; operacionais (incluindo a comercialização); financeiras; e com capital físico. Outro input importante é o patrimônio líquido (equity) das operadoras, que representa o capital das operadoras de planos de saúde. Além das despesas e do patrimônio líquido, Carrington, Coelli e Rao (2011) chamam a atenção que, para cálculo de eficiência técnica, é necessário o cômputo de indicadores físicos de inputs. Para isso, deflacionam os custos administrativos usando um deflator específico, de modo a gerar uma medida de input físico.

Os outputs mais utilizados são os seguintes: quantidades de beneficiários; receitas totais; e receitas de contraprestações. Hashimoto (2010) inclui as quantidades de consultas por beneficiários - poderíamos, eventualmente, incluir quantidades de cirurgias, e as quantidades de exames por beneficiários. Mas as quantidades de atendimentos, em geral, são indicadores algo controversos: valores excessivamente elevados podem significar uma clientela adoecida por falta de cuidados. Por sua vez, valores muito baixos desses indicadores podem indicar pouca cobertura, ou dificuldades de acesso. A rigor, o que interessa é a saúde (bem final) e não os atendimentos (bens intermediários). Existiria a necessidade de separação de determinantes da saúde dos beneficiários que não dependem da ação das operadoras de planos de saúde, como os cuidados tomados pelas próprias pessoas (prática de exercícios físicos, não fumar etc.) e também bens e serviços fornecidos pelo setor público (vacinação, saneamento etc.).

Alves (2009) prefere enfatizar o papel das operadoras como empresas que vendem seguros e prestam serviços de agregação e gerenciamento de riscos. Por isso, o trabalho utiliza os inputs usualmente representativos de despesas operacionais, financeiras e de capital físico. Entretanto, como outputs, o autor, em abordagem securitária, usa apenas os benefícios pagos por eventos e sinistros indenizáveis líquidos, e a soma desses benefícios com as reservas garantidoras de pagamentos de benefícios e sinistros futuros, que são as adições às provisões técnicas.

Outro ponto importante é a qualidade da prestação de serviços. Carrington, Coelli e Rao (2011) alegam que não utilizaram indicadores de qualidade devido ao baixo impacto deles sobre a eficiência, medida em um modelo econométrico não especificado. Carrington, Coelli e Rao (2008) apresentam, como medidas de qualidade, variáveis representativas de satisfação do consumidor como as porcentagens de: beneficiários dos planos retidos por mais de dois anos; crescimento anual de beneficiários; e solicitações de serviços de saúde (ancillary services), como consultas, exames, diagnósticos, terapias, transportes etc., processadas em menos de cinco dias. Os demais autores citados não mencionam indicadores de qualidade, mas esses indicadores são, frequentemente, incorporados em outros contextos regulatórios. ${ }^{12}$ Poderíamos pensar como indicadores de qualidade as seguintes variáveis: as quantidades de reclamações; processos na justiça; e punições pela ANS, rotatividade de prestadores de assistência (alterações muito frequentes na rede referenciada) etc.

O trabalho de Yuda (2016) tem uma característica que o difere dos demais textos que citamos: trata de seguros públicos de saúde. Assim, como outputs, além de utilizar as receitas líquidas obtidas com a comercialização dos seguros, esse autor considera a esperança de vida das populações de cada município, dado que os municípios são os gestores dos planos e exercem o papel de seguradoras no Japanese National Health Insurance (JNHI). Como inputs, são utilizados: os tamanhos do pessoal administrativo e da equipe médica; a quantidade de instituições médicas; e o patrimônio líquido (equity) - que é a proxy usual para o input representativo do capital.

\subsection{O fator $\mathrm{X}$ na atual regra de reajuste de preço da ANS}

Como já visto, não é a partir da regra de preços que se constrói o YC mais adequado nesse mercado. Contudo, como veremos mais adiante, outro ponto intrigante é o uso, tão somente, da despesa assistencial dos agentes mais ineficientes para se construir o FGE. ${ }^{13}$ A medida de eficiência ideal seria multidimensional, de modo que a justificativa para o uso da despesa assistencial como variável-chave precisa ser justificada pela ANS.

11. Para detalhada comparação entre DEA e SFA, ver Bogetoft e Otto (2011).

12. Ver Marinho e Resende (2019).

13. A NT no 27 de 2018 explicita o cálculo do FGE. 
Esse suposto FGE cumpriria o papel do fator X de repasse de ganhos de produtividade do monopolista para os consumidores na regra de teto de preços (price cap), empregado na regulação de tarifas de serviços públicos de monopólios naturais, tais como distribuição de energia, saneamento básico etc. De fato, o Estado tem interesse que a empresa regulada persiga ganhos de eficiência. Se eles forem bem calibrados, a empresa poderá reduzir preços reais (isto é, fazer reajustes de preços inferiores à inflação) sem comprometer sua solvência. Entretanto, além dessa medida da eficiência, há duas decisões da ANS que precisariam ser igualmente justificadas.

O FGE é todo construído a partir de estatísticas da VDA. Contudo, nem a VDA, tampouco uma simples estatística construída a partir dela, se constituem em um indicador de produtividade, como assumido nas NTs $\mathrm{n}^{\mathrm{os}} 27 / 2018$ e 30/2018. Afinal de contas, produtividade é o quociente entre quantidade utilizada de um produto e a quantidade utilizada de um insumo usado na geração desse produto. Em outras palavras, não se pode recorrer à curva de distribuição estatística da VDA (nem isoladamente, nem em combinação com outros indicadores) para se construir uma medida de eficiência econômica.

Eficiência não é apenas a distância entre um ponto da distribuição das despesas e alguma medida de tendência central (média, mediana ou moda) ou de dispersão (intervalo interquartílico), ${ }^{14}$ ou de qualquer outro ponto arbitrário dessa distribuição. Antes, é um conceito que em suas diversas modalidades (eficiência técnica, eficiência de escala, eficiência alocativa e seus desdobramentos) procura medir a relação entre custos e benefícios ótimos nos processos produtivos dos agentes econômicos. A VDA é tão somente uma média ponderada de despesas assistenciais, que não considera o conjunto de custos (ou insumos) e benefícios (ou produtos) gerados nas atividades das operadoras de planos de saúde. Não há como falar de eficiência a partir de valores relativamente elevados ou baixos da VDA, se desconectada dos produtos que geraram as despesas. Em 2010 e 2011, segundo a NT no 30/2018, houve uma tentativa de utilização de um modelo de DEA no cálculo da eficiência setorial. De acordo com essa NT,

entre 2010 e 2011 e tomando por referência teórica a Análise Envoltória de Dados e a experiência do órgão regulador australiano Private Health Insurance Administration Council (PHIAC) foi proposto um fator de eficiência que tinha as despesas administravas como insumo e número de beneficiários, receitas financeiras e receitas de contraprestações como produtos. Além de ser considerado complexo, o mesmo não atendia a finalidade de incentivar operadoras a atuarem como gestoras de assistência à saúde de seus beneficiários, uma vez que o único insumo eram as despesas administrativas (ANS, 2018b, seção 5.1).

Posteriormente, uma proposta feita por Andrade (2015) baseava-se também em DEA e incluía as despesas assistenciais (op. cit., p. 26-27). Mas essa proposta também não foi adotada, sem que saibamos as razões para tal.

Nesse cenário, não vislumbramos uma justificativa baseada em teoria econômica para a adoção do terceiro quartil da distribuição da variável de desempenho como base para o cálculo do benchmark. A distribuição da eficiência estimada em alguns dos métodos não paramétricos mais comuns (DEA, free disposal hull ${ }^{15} \mathrm{e}$ índice de Malmquist) é desconhecida, porque provém de um processo de geração de dados desconhecido nesses métodos baseados em programação matemática (Bogetoft e Otto, 2011). ${ }^{16}$ No caso dos métodos paramétricos, notadamente SFA, a distribuição da eficiência é, de modo usual, suposta normal - truncada, meia-normal, exponencial ou gama. Portanto, a posição de cada unidade produtiva no ranking dos escores é indeterminada ex-ante, dependendo de estimação nos modelos, com base nos dados. Não parece razoável fixar o benchmark em posição definida a priori por algum percentil da distribuição dos escores.

O diagrama de caixa (boxplot), utilizado pela ANS, constrói uma quantidade fixa de operadoras em cada quartil. Esse procedimento é arriscado, pois a eficiência econômica real costuma ser concentrada em torno do supremo ${ }^{17}$ da distribuição e assimétrica à esquerda, visto que a capacidade de discriminação dos modelos é limitada, e sempre existe a possibilidade de que várias unidades produtivas sejam assinaladas como eficientes na presença de critérios múltiplos (múltiplos indicadores) de análise (efficiency by virtue of specialization).

Mas, ainda que se admitisse, para fins de argumentação, o uso da distância média ponderada dos agentes mais ineficientes em relação ao benchmark como a base para definir o ganho de eficiência, note que isso uniformizaria o tamanho dos ganhos de eficiência para aqueles considerados ineficientes, mas também, por incrível que pareça, para

14. O intervalo interquartílico é uma medida de dispersão que mede a distância entre o primeiro quartil (percentil 25) e o terceiro quartil (percentil 75) de uma distribuição de probabilidades.

15. Envoltório de livre descarte (Deprins, Simar e Tulkens, 1984).

16. Isso significa que esses métodos são agnósticos quanto à especificação da função de probabilidade as variáveis de desempenho e, portanto, não fornecem nenhuma justificativa para a escolha de um quintil específico da distribuição. Seria necessário buscar outra fundamentação para essa escolha, que até o presente momento não foi explicitada pela ANS.

17. O supremo é a menor das cotas superiores de um conjunto $A$. Uma cota superior a de um conjunto $A$ é um valor tal que todos os elementos do conjunto $A$ são menores ou iguais do que $a$. A diferença entre um supremo e um máximo é que uma cota não necessariamente pertence ao conjunto $A$, enquanto o máximo, necessariamente, pertence ao conjunto $A$. 
os considerados eficientes (operadoras e planos). Isso significa que os eficientes precisariam aumentar sua dita eficiência na mesma escala que os ineficientes. Isso é viável? Afinal, se os eficientes usam "eficientemente" seus insumos em seus processos produtivos, dado seu nível de preço, são eles que mais precisariam inovar em tecnologia e/ou gestão para deslocar sua fronteira de eficiência, enquanto seria razoável imaginar que os ineficientes teriam que adquirir tão somente boas práticas no mercado para fazerem seu catching up em direção aos mais eficientes.

Dito de outra maneira: admitindo retornos decrescentes dos investimentos em expansão da produtividade, não nos parece justo atribuir a ambos os grupos - eficientes e ineficientes - a mesma tarefa de redução de custos, ou mesmo, se fosse aplicável e viável, de melhoria da qualidade - caso o indicador de eficiência incorporasse alguma medida de desempenho na qualidade do atendimento. A solução seria separar a mudança na eficiência técnica (o deslocamento da fronteira de possibilidades de produção) do catching up das firmas ineficientes (Coelli et al., 2003) - além de controlar para mudanças de escala e alocativas (Kumbhakar, Denny e Fuss, 2000).

Seria, portanto, necessário fazer uma triagem de tais despesas assistenciais. Esse seria um passo delicado, requerendo um trabalho cuidadoso e criterioso, para não dizer que a definição de sua metodologia certamente suscitaria uma pesada disputa entre as partes envolvidas (stakeholders). Para fins de calibragem do FGE, nota-se ainda que a premiação dos ganhos de eficiência retomaria o conceito da competição por desempenho (YC), pois se compararia à VDA de um quarto das operadoras supostamente mais eficientes para induzir as menos eficientes a alcançar a fronteira de eficiência. Desse modo, persistiriam algumas ressalvas finais ao modelo proposto (ANS, 2018a, p. 4-5).

1) A redação ficou pouco clara, uma vez que supostamente as operadoras mais "eficientes" seriam aquelas que apresentassem menor VDA: “(...) a meta é calculada pelo somatório das distâncias das operadoras que estão acima do terceiro quartil, uma vez que valores de VDA até o terceiro quartil representam a eficiência média do modelo proposto" (NT no 27/2018). ${ }^{18}$ A meta está portanto, em reduzir o VDA em direção a um nível de despesas relativamente alto, muito longe da fronteira (que seria o primeiro quartil); isso é justificado na NT nº 1/2019 pela distinção entre benchmarkings voltados para o representante médio (average benchmark), exemplificado pelo yardstick e pelo uso de métricas como a produtividade total dos fatores, e os voltados para a melhor prática (frontier benchmark) - ver próximo item.

2) Sanciona-se que ganhos de eficiência passados sejam projetados para frente. Ora, dado que não se busca a fronteira, mas algo bem abaixo dela, esse mecanismo pode gerar um incentivo perverso no longo prazo, no sentido que haja um race to the bottom, isto é, que as operadoras prefiram se rebaixar para não puxarem o FGE para cima - isso aconteceria por causa da natureza retrospectiva (backward looking) da regra. ${ }^{19}$

Como bem assinalam Bogetoft e Otto (2011, p. 17):

As análises modernas de benchmarking usam cada vez mais os métodos de análise das melhores práticas ou fronteira. A ideia é modelar a fronteira da tecnologia em vez de modelar o uso médio das possibilidades tecnológicas. Isso tem vantagens metodológicas e práticas. Um aspecto muito prático é que frequentemente é mais interessante aprender com as melhores performances do que imitar as medíocres.

O que pode acontecer quando os benchmarks estão localizados no interior do conjunto de possibilidades de produção, em vez de na fronteira, é o surgimento de efeitos perversos como: a degradação do desempenho pelas firmas eficientes para aumentar lucros ou folga operacional, ou para aumentar o nível do benchmark futuro (ratchet effect). ${ }^{20}$ Jamasb e Söderberg (2010) reportam que uma regulação por norma média implementada no setor de distribuição de energia da Suécia propiciou que empresas com desempenho melhor que os benchmarks agissem oportunisticamente e aumentassem seus lucros ou ineficiências econômicas. ${ }^{21}$

\footnotetext{
18. A rigor, matematicamente a "eficiência média" é bem diferente da média dos $75 \%$ dos agentes com menor VDA. O expurgo faz com que o VDA "médio" (aparado) seja menor que o VDA médio geral, mas ainda assim é bem acima da fronteira, e, portanto, correspondentemente representa uma eficiência média mais baixa (já que a eficiência medida pela VDA cresce quando a VDA cai).

19. Em sentido diverso, criar uma metodologia forward looking não é trivial e envolve a coleta de inputs e outputs que permitam a estimação de funções de produção ou de custos. Como projetar ganhos de eficiência prospectivos? Bragança e Camacho (2012) discorrem sobre esse problema nos setores de infraestrutura. Basicamente as opções seriam criar uma empresa modelo fictícia (abordagem de engenharia); usar modelos de regressão para projetar ganhos na produtividade total dos fatores; índices históricos; e métodos de fluxo de caixa descontado. Essas opções deveriam ter sido listadas pela ANS, de modo que ela apontasse quais os prós e contras analisados de cada uma para se justificar a alternativa escolhida.

20. Para mais informações, ver Joskow (2007) e Armstrong e Sappington (2005).

21. Fique bem claro - se ainda não tiver ficado anteriormente - que estamos falando de eficiência no sentido de produtividade total de fatores, ainda que esses fatores não possam ser tipificados como capital ou trabalho, por exemplo. Isso significa que a distância em relação à fronteira já está controlada pela escala de produção. Assim, operadoras menores e que não auferem ganhos de escala podem, mesmo assim, ser eficientes e ou mais próximas da fronteira que operadoras maiores. Portanto, não se pode afirmar ex ante que haja qualquer correlação entre o tamanho da operadora e sua distância da fronteira, e não se pode alegar a priori que operadoras menores tenham um esforço maior ou menor de convergir para a fronteira.
} 
a regulação por teto de preços envolve a fixação de limites máximos para os aumentos de preços. O teto é ajustado apenas com alguma defasagem. As empresas individuais mantêm um incentivo para reduzir custos e produzir com eficiência, porque no curto prazo seu comportamento não afeta os preços que elas podem cobrar, e poderão reter lucros adicionais resultantes da redução de custos. Além disso, informações assimétricas propiciam algumas rendas informacionais. Para definir os tetos de preços, o regulador precisa de informações sobre a tecnologia das empresas. O regulador terá que fazer uma estimativa da melhoria da eficiência para os próximos anos. Quando informações comparativas de desempenho são usadas para fornecer essas informações, o regulamento do teto de preço contém um elemento de YC.

Em suma, a opção por um esquema de benchmarking pelo desempenho médio é cheia de armadilhas que parecem ter sido ignoradas pela ANS. O modelo puro de YC proposto por Shleifer (1985) estabelece que o preço regulado (ou seu reajuste) seja uma combinação convexa de seu próprio custo com os das firmas usadas como referência. No limite, como a regra é retrospectiva (backward looking), o ideal é que o peso dado ao seu próprio custo seja zero, para que a firma regulada não seja incentivada a ter um desempenho pior de modo a suavizar o ganho de produtividade a ser descontado de seu reajuste. Além do detalhe importante, e já mencionado, que as firmas de comparação não sejam competidoras diretas da firma regulada em questão. Ora, isso implica que cada firma tenha seu próprio limite de reajuste, e não que se imponha um teto de reajuste igual para todos.

Fazendo da maneira proposta por Shleifer (1985), a empresa regulada terá incentivo a ter um desempenho melhor que a média sem ela, para que possa usufruir de uma maior folga no reajuste e, portanto, maiores lucros. Com essa competição pelo desempenho, ganha o consumidor, que usufrui de ganhos de produtividade maiores, e que, quanto maiores são na média, mais são apropriados por ele na forma de reajustes menores de preços. Já na regra implementada pela ANS, a empresa regulada, se tiver um desempenho medíocre - admitamos, exclusivamente para fins de raciocínio, que fosse a própria VDA -, mas dentro do intervalo do mínimo ao terceiro quartil, vai afetar diretamente o cômputo do desempenho - pois a "média" a inclui -, beneficiando-se de um fator de eficiência mais generoso (menor) e, portanto, de um reajuste maior.

Diante dessas considerações, é importante que a sociedade debata os aspectos técnicos e operacionais dessa nova metodologia e, sobretudo, que ela seja testada retrospectivamente para avaliarmos seus possíveis impactos, em especial se a nova metodologia de reajuste dos planos de saúde refletirá melhor os custos, os preços e a eficiência do setor regulado.

\section{UMA QUEBRA DE PARADIGMA É NECESSÁRIA?}

Quando nos lançamos à empreitada de examinar a regulação da ANS em vigor, a primeira pergunta que nós e nossos interlocutores e pareceristas fizemos foi: como se regula esse setor em outros países?

Essa pergunta é capciosa, pois pressupõe-se que outros países tenham um mercado de planos de saúde privados tão forte como o nosso, ou que adotem um sistema de seguro-saúde obrigatório. Bem, a verdade é que, quando se pensa em regulação do setor de saúde nos países desenvolvidos, o primeiro pensamento é como conter os custos da provisão dos serviços. Essa é a tônica do último relatório da Organização para a Cooperação e Desenvolvimento Econômico (OCDE) e da Organização Mundial da Saúde (OMS) sobre determinação e preços de saúde em seus países-membros (Barber, Lorenzoni e Ong, 2019). Uma regulação que incide sobre o produto, o plano de saúde, pressupõe que a contenção do preço final servirá de pressão para contenção dos custos ao longo da cadeia. Essa abordagem tem várias consequências importantes, entre as quais apresentamos quatro que se destacam.

1) Os diferentes graus de competição entre operadoras nos vários mercados relevantes geográficos e ou de produtos, bem como os graus de competição das prestadoras e, consequentemente, o balanço de forças entre esses importantes atores, são ignorados. A falta de negociações multilaterais, por exemplo, acaba sobrecarregando no caso brasileiro - o Conselho Administrativo de Defesa Econômica (Cade) com numerosas investigações (e condenações) de associações médicas por formação de cartel ao tentarem impor tabelas de preços.

2) O papel da operadora na geração de ganhos de eficiência é bastante limitado. Ela tem que agir como um "principal” tentando extrair das prestadoras ("agentes") um maior esforço de redução de custos. Claro, operadoras grandes podem ter estrutura organizacional, corpo técnico e ou disponibilidade de recursos para realizarem esse trabalho de racionalização de procedimentos junto às prestadoras, ou, em última análise, podem acabar recorrendo à integração vertical com elas para assumir o controle desses processos.

3) Os problemas de risco moral ou desalinhamento de interesses em geral, tais como a sobreutilização de medicamentos, órteses, próteses e materiais especiais (OPMEs), exames e outros insumos médicos, e o excesso de utilização de novas tecnologias com relação custo-benefício duvidoso.

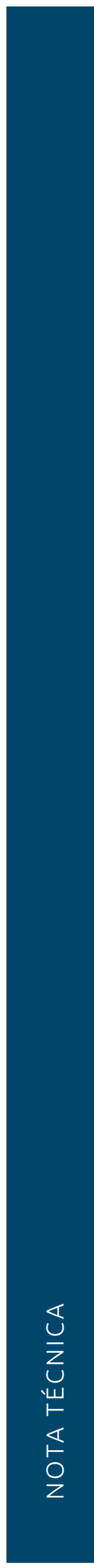


4) A precificação de serviços de saúde contratados pelo SUS junto a prestadores privados tipicamente não é feita em sincronização com a precificação entre entes privados (operadoras e prestadoras).

Países com uma atuação forte do governo no setor de saúde têm, em comum, definir os valores das contribuições de cada agente ou cidadão predominantemente com base em critérios distributivos e de solidariedade social, e menos em virtude dos custos trazidos pelo paciente ao sistema. Esses valores podem ser repartidos entre o próprio Tesouro, os segurados e seus empregadores. A busca por eficiência deriva, portanto, das limitações orçamentárias e da impossibilidade de se aumentar indefinidamente a arrecadação de impostos.

Alguns países utilizam sistemas de seguro-saúde e suas autoridades de saúde têm alguma atuação em regulá-los, ainda que parcialmente - deixando alguns dos preços para negociações coletivas e individuais. Barber, Lorenzoni e Ong (2019, p. 77-78) listam nesse grupo Japão, Alemanha, Austrália, Coreia do Sul, o Medicare dos Estados Unidos e o estado norte-americano de Maryland:

onde os preços são usados como instrumentos para atingir as metas políticas, é necessário um forte papel central na orientação do processo. Entre as configurações deste estudo, incluindo o programa Medicare dos Estados Unidos e o sistema de pagamento integral (all-payer) de Maryland, os governos nacionais têm desempenhado papéis ativos na definição e na regulação de preços para alcançar os objetivos de políticas. Em muitas configurações, as estruturas de preços e taxas são determinadas centralmente (ou seja, França, Japão, República da Coreia e especialistas australianos que trabalham em particular). Em países como a Alemanha, as taxas também podem ser adaptadas às especificidades do estado, refletindo a estrutura federal do país.

Além desses, os Países-Baixos adotam definições unilaterais de alguns preços.

Quando os preços são administrados, dá-se, segundo Barber, Lorenzoni e Ong (2019), uma competição por desempenho (YC). Segundo os autores, assim como as negociações coletivas, o método administrativo unilateral elimina a discriminação de preços, uma vez que é estabelecido um preço fixo. Além disso, em comparação com negociações individuais, a fixação unilateral de preços administrativos incorre em custos administrativos mais baixos por seguradoras e sistemas de saúde, mas podem ser aplicadas despesas regulatórias relativamente menores (Anderson e Herring, 2014). Os preços dos serviços hospitalares geralmente são fixados unilateralmente e podem incluir pagamentos adicionais para garantir metas mais amplas de saúde pública, como equidade e acesso.

Vale notar que um sistema administrativo unilateral de fixação de preços requer informações, incluindo custo, volume e desfechos, visto que os preços geralmente são baseados em custo (médio, marginal) ou são normativos (eficientes). Os fatores de ajuste são usados pelo provedor ou pelo serviço para contabilizar os recursos que afetam o custo de produção; por exemplo, tipo ou tamanho do hospital, localização, complexidade do paciente e atividades de ensino.

Nas jurisdições em que os preços são regulados, os fornecedores competem pelo volume e pela qualidade do serviço, e não pelo preço, para atrair consumidores. Dessa forma, pressões para reduzir custos podem resultar em ganhos de eficiência, e não em qualidade reduzida. Em Maryland, a abordagem all-payer (que é uma espécie de negociação multilateral entre operadoras e prestadoras) resultou no fechamento de instalações menores e hospitais de alto custo, resultando em ganhos de eficiência e melhorias no fluxo de pacientes (Murray e Berenson, 2015). As abordagens unilaterais de fixação de preços do Medicare e de Maryland foram combinadas com incentivos de qualidade que promovem diretrizes clínicas baseadas em evidências e fornecem incentivos para reduzir as readmissões hospitalares. A fixação de preços por reguladores também ajuda a melhorar a estabilidade financeira dos hospitais.

Portanto, entendemos que, se quisermos contribuir efetivamente com a regulação direta dos planos, o mais sensato é ter um sistema de custos e produtividade de saúde, que abarque os diversos serviços de saúde públicos e privados. É nas prestadoras que certamente está o maior potencial de ganhos de eficiência operacional, enquanto tudo que podemos esperar de ganho de eficiência para as operadoras é uma maior agilidade que economize despesas administrativas.

\section{CONSIDERAÇÕES FINAIS}

Diante da explosão dos preços, que, em conjunto com o crescimento do desemprego, contribuiu para a recente expulsão de 3 milhões de usuários do mercado (Ocké-Reis, Fiuza e Coimbra, 2019), a diretoria colegiada da ANS aprovou essa nova metodologia, baseada na VDA, calibrada pela produtividade e faixa etária. Cabe arguir: será essa regra capaz de medir os custos, os preços e a eficiência do setor, visando refrear o aumento continuado dos preços em face da consolidação de grandes conglomerados? Por que deixaram de fora novamente os planos empresariais, os quais, a um só tempo, representam a maioria do mercado e cujos contratos podem ser rescindidos unilateralmente? Em particular, decididamente, a fórmula de reajuste de preços de planos de saúde individuais não comunga com as melhores práticas de benchmarking, pois assenta-se em medidas de eficiência equivocadas. 
O que propomos nesta nota é rever o FGE para que: $i$ ) se baseie em medidas de eficiência consagradas na literatura, seja usando DEA, seja usando SFA; ii) utilize efetivamente uma fronteira de eficiência em vez de uma eficiência "média" (que, a rigor, nem média é), especialmente se for mantido o caráter retrospectivo da fórmula; iii) requeira menores ganhos de eficiência (menores X) dos agentes que já estão na fronteira ou mais próximos dela, e maiores ganhos (maiores X) dos mais ineficientes - os valores de X podem ser individuais ou por grupos (clusters); e iv) se, ainda assim, persistir a opção pelo desempenho médio, que os desempenhos próprios dos agentes sejam estornados do cômputo da fórmula, para que eles não tenham o condão de afetar o resultado dela, o que seria um incentivo perverso.

Também propomos que sejam abertas as discussões - na medida em que haja condições políticas para tal - no sentido de: $i$ ) atribuir às operadoras apenas metas de desempenho dentro do que lhes cabe fazer, isto é, perseguir a sua eficiência operacional na gestão de suas carteiras e redes de prestadores; ii) desenvolver uma metodologia que permita aferir o desempenho, com vistas - em um prazo não muito distante - à adoção de YC também no âmbito dos prestadores, principalmente hospitais e clínicas, os quais, de acordo com Carrington, Coelli e Rao (2011), oferecem as maiores oportunidades de crescimento da produtividade setorial.

\section{REFERÊNCIAS}

ALVES, S. L. Eficiência das operadoras de planos de saúde. Revista Brasileira de Risco e Seguro, Rio de Janeiro, v. 4 , n. 8, p. 87-112, 2009.

ANDERSON, G.; HERRING, B. The all-payer rate setting model for pricing medical services and drugs. AMA Journal of Ethics, v. 15, n. 8, p. 770-775, 2015.

ANDRADE, M. V. Documento técnico contendo a avaliação da metodologia e dos resultados do price cap desenvolvidos em estudos da Agência Nacional de Saúde Suplementar (ANS), que visam estabelecer novos critérios de reajustes dos planos individuais regulamentados, contendo ainda parecer sobre a reprodutibilidade do modelo na Saúde Suplementar. Brasília: ANS, mar. 2015.

ANDRADE, M. V. et al. Mercados e concentração no setor suplementar de planos e seguros de saúde no Brasil. Pesquisa e Planejamento Econômico, v. 42, n. 3, p. 329-361, 2012.

ANS - AGÊNCIA NACIONAL DE SAÚDE SUPLEMENTAR. Nova metodologia de cálculo dos reajustes dos planos de assistência médica à saúde. Rio de Janeiro: ANS, 2011. (Nota Técnica, n. 1180).

Descrição de proposta de metodologia de cálculo dos reajustes dos planos individuais de cobertura médico-hospitalar regulamentados pela Lei no 9.656/1998. Rio de Janeiro: ANS, 2018a. (Nota Técnica, n. 27.) Disponível em: <https://tinyurl.com/y4szlgkt>. Acesso em: 2 set. 2020.

Descrição de proposta de metodologia de cálculo dos reajustes dos planos individuais de cobertura médico-hospitalar regulamentados pela Lei no 9.656/1998 após realização da Audiência Pública em 13 de novembro de 2018. Rio de Janeiro: ANS, 2018b. (Nota Técnica, n. 30).

Resolução Normativa no 441, de 19 de dezembro de 2018. Rio de Janeiro: ANS, 2018c. (Anexo I). Disponível em: <https://bit.ly/3gjNQgL>. Acesso em: 2 set. 2020.

ANS se reúne com órgãos de defesa do consumidor e entidades ligadas ao setor para apresentar novo cálculo do reajuste. Rio de Janeiro: ANS, 2018d. Disponível em: <https://bit.ly/32ixfok>. Acesso em: 20 fev. 2019.

Valor do Fator de Ganhos de Eficiência (FGE) a ser aplicado na fórmula de reajuste dos planos individuais no quadriênio 2019-2020-2021-2022. Rio de Janeiro: ANS, 2019. (Nota Técnica, n. 1). Disponível em: <https://bit.ly/3hkgjUS>. Acesso em: 14 jan. 2020.

ARMSTRONG, M.; COWAN, S.; VICKERS, J. Regulatory reform: economic analysis and British experience. MIT press, 1994.

ARMSTRONG, M.; SAPPINGTON, D. E. M. Recent developments in the theory of regulation. In: ARMSTRONG, M.; PORTER, R. (Eds.). Handbook of industrial organization. New York: North-Holland, 2005. v. 3. p. 1557-1687.

ARON, D. J.; BURNSTEIN, D. E. Regulatory Policy and the reverse cellophane fallacy. Journal of Competition Law and Economics, v. 6, n. 4, p. 973-994, 2010.

BARBER, S. L.; LORENZONI, L.; ONG, P. Price setting and price regulation in health care: lessons for advancing universal health coverage. Geneva: OECD; World Health Organization, 2019.

BAUMOL, W. J. Health care, education, and cost disease: a looming crisis for public choice. Choice, v. 77, n. 1, p. 17-28, 1993.

BERNSTEIN, J. I.; SAPPINGTON, D. E. Setting the X factor in price-cap regulation plans. Journal of Regulatory Economics, v. 16, n. 1, p. 5-26, 1999. 
BOGETOFT, P.; OTTO, L. Benchmarking with DEA, SFA and R. New York: Springer, 2011.

BRAGANÇA, G. G. F.; CAMACHO, F. T. Uma nota sobre o repasse de ganhos de produtividade em setores de infraestrutura no Brasil (fator X). Radar: tecnologia, produção e comércio exterior, v. 22, p. 7-16, 2012.

BRASIL. Ministério da Fazenda. Nota Técnica SEI no 10. Brasília: MF, 2018.

CARRINGTON, R.; COELLI, T.; RAO, D. S. P. Regulation of private health insurance premiums: can performance assessment play a greater role? Brisbane: The University of Queensland, 2008. (Working Paper, n. 4).

Australian private health insurance productivity growth: is there scope to limit premium increases? The Economic Record, v. 87, n. 276, p. 125-139, Mar. 2011.

COELLI, T. et al. A primer on efficiency measurement for utilities and transport regulators. Washington: The World Bank, 2003.

CPB - NETHERLANDS BUREAU FOR ECONOMIC POLICY ANALYSIS. Yardstick competition: theory, design, and practice. The Hague: CPB, 2000. (Working Paper, n. 133).

CUTLER, D. M.; ZECKHAUSER, R. J. The anatomy of health insurance. In: CULYER, A. J.; NEWHOUSE, J. P. (Eds.). Handbook of health economics. 4. ed. Amsterdam: Elsevier, 2000. v. 1A. p. 563-643.

DEPRINS, D.; SIMAR, L.; TULKENS, H. Measuring labor-efficiency in post offices. In: TULKENS, H. Public goods, environmental externalities and fiscal competition. Boston, MA: Springer, 2006. p. 285-309.

FERNANDES, H. R.; MARINHO, A. A eficiência dos juizados especiais estaduais brasileiros e sua atual estrutura. Revista Brasileira de Economia, v. 72, p. 313-329, 2018.

FRIED, H. O.; KNOXX LOVELL, C. A.; SCHMIDT, S. (Eds.). The measurement of productive efficiency and productivity growth. Oxford University Press, 2008. p. 20.

HASHIMOTO, P. A. Análise de eficiência técnica das operadoras de planos de saúde com a utilização da análise envoltória de dados. 2010. Dissertação (Mestrado) - Universidade do Estado do Rio de Janeiro, Rio de Janeiro, 2010.

JAMASB, T.; SODDERBERG, M. The effects of average norm model regulation: the case of electricity distribution in Sweden. Review of Industrial Organization, v. 36, n. 3, p. 249-269, 2010.

JOSKOW, P. Incentive regulation in theory and practice: electric distribution and transmission networks. In: ROSE, N. (Ed.). Economic regulation and its reform: what have we learned? Chicago: University of Chicago Press, 2007.

KOOPMANS, T. Activity analysis of production and allocation. New York: John Wiley\&Sons, 1951.

KUMBHAKAR, S.; DENNY, M.; FUSS, M. Estimation and decomposition of productivity change when production is not efficient: a panel data approach. Econometric Reviews, v. 19, n. 4, p. 312-320, 2000.

LITTLECHILD, S. Regulation of British telecommunications' profitability: report to the Secretary of State. Londres: Department of Industry, 1983.

MARINHO, A.; CARDOSO, S. S.; ALMEIDA, V. V. Avaliação comparativa de sistemas de saúde com a utilização de fronteiras estocásticas: Brasil e OCDE. Revista Brasileira de Economia, v. 66, n. 1, p. 3-19, jan-mar. 2012.

MARINHO, A.; RESENDE, M. Service quality in electricity distribution in Brazil a Malmquist approach. Annals of Public and Cooperative Economics, v. 90, p. 687-712, 2019.

MURRAY, R.; BERENSON, R. A. Hospital rate setting revisited: dumb price fixing or a smart solution to provider pricing power and delivery reform? The Urban Institute, 2015.

OCKÉ-REIS, C. O.; CARDOSO, S. S. Uma descrição do comportamento dos preços dos planos de assistência à saúde: 2001-2005. Rio de Janeiro: Ipea, 2006. (Texto para Discussão, n. 1232).

OCKÉ-REIS, C. O.; FIUZA, E. P. S.; COIMBRA, P. H. Inflação dos planos de saúde: 2000-2018. Rio de Janeiro: Ipea, maio 2019. (Nota Técnica, n. 54).

PIETROBON, L.; PRADO, M. L. D.; CAETANO, J. C. Saúde suplementar no Brasil: o papel da Agência Nacional de Saúde Suplementar na regulação do setor. Revista de Saúde Coletiva, v. 18, p. 767-783, 2008.

SHLEIFER, A. A theory of yardstick competition. RAND Journal of Economics, v. 16, n. 3, p. 319-327, 1985.

TRAIN, K. E. Optimal regulation: the economic theory of natural monopoly. 1. ed. MIT Press Books, 1991.

YUDA, M. Inefficiencies in the Japanese National Health Insurance System: a stochastic frontier approach. Journal of Asian Economics, v. 42, p. 65-77, 2016. 
ANS - AGÊNCIA NACIONAL DE SAÚDE SUPLEMENTAR. Qualificação da saúde suplementar: uma nova perspectiva no processo de regulação. Rio de Janeiro: ANS, 2004.

Relatório da Audiência Pública no 10: audiência pública sobre política de preços e reajustes na saúde suplementar. Rio de Janeiro: ANS, 2018.

BRASIL. Resolução Normativa no 441, de 19 de dezembro de 2018. Estabelece critérios para cálculo do reajuste máximo das contraprestações pecuniárias dos planos privados de assistência à saúde individuais ou familiares, médico-hospitalares, com ou sem cobertura odontológica, que tenham sido contratados após 1o de janeiro de 1999 ou adaptados à Lei no 9.656, de 3 de junho de 1998. Diário Oficial, Brasília, 20 dez. 2018. Disponível em: <https://bit.ly/3lKNBPF> . Acesso em: 12 fev. 2019.

DEE - DEPARTAMENTO DE ESTUDOS ECONÔMICOS. Atos de concentração nos mercados de planos de saúde, hospitais e medicina diagnóstica. Brasília: DEE, 2018.

DE NEGRI, F. As tecnologias da informação podem revolucionar o cuidado com a saúde? In: IPEA - INSTITUTO DE PESQUISA ECONÔMICA APLICADA. Radar: tecnologia, produção e comércio exterior, Brasília, v. 57, p. 31-33, 2018.

DUCLOS, M. T. Atos de concentração, poder de monopsônio e restrições verticais no mercado de saúde suplementar. In: FIUZA, E. P. S.; MOTTA, R. S. (Orgs.). Métodos quantitativos em defesa da concorrência e regulação econômica. Rio de Janeiro: Ipea, 2016.

RAGAZZO, C. E. J.; MACHADO, K. Desafios da análise do CADE no setor de planos de saúde. São Paulo: LCTE, 2011. Disponível em: <https://bit.ly/2FMpfo9>. Acesso em: 20 fev. 2019.

SANTOS, T. Determinação de mercados relevantes no setor de saúde suplementar. Brasília: Seae/MF, 2008. (Documento de Trabalho, n. 46). 


\section{Definição de mercado relevante na saúde suplementar}

Na audiência pública onde se discutiu a nova regra de reajuste (ANS, 2018), a metodologia anterior da Agência Nacional de Saúde Suplementar (ANS) foi alvo de duras críticas, uma vez que seu modelo de yardstick competition (YC) não estaria comparando produtos diferentes de mercados diferentes - mecanismo que, em tese, seria necessário para o sucesso do modelo.

Não temos evidências para corroborar esse argumento, pois desconhecemos estudos rigorosos que demostrem se os planos individuais e os coletivos pertencem a mercados relevantes diferentes.

É importante notar que a definição de mercado relevante foi criada para atender a determinadas ações administrativas requeridas para o funcionamento adequado das agências antitruste. Esse conceito é aplicado, justamente, para elucidar se dois ou mais agentes econômicos competem entre si pelos mesmos consumidores de um subconjunto de produtos e/ou serviços. Por exemplo, na área da saúde suplementar, pode ser irrelevante o fato de a operadora de plano se organizar enquanto cooperativa, autogestão, administradora de benefícios ou seguradora especializada em saúde: para os consumidores, planos de saúde com diferentes prêmios, copagamentos, carências etc. podem ser substitutos entre si. Desse modo, em primeiro exame, admite-se que a distinção menos problemática para separar os mercados seria entre planos ambulatoriais, hospitalares e odontológicos.

De qualquer maneira, as referências mais citadas sobre mercados relevantes na saúde suplementar são de Santos (2008) e Andrade et al. (2012). Esse último estudo parte da premissa que os planos individuais e coletivos pertencem a mercados relevantes de produtos distintos. Por sua vez, Santos (2008) adota hipóteses preliminares, evidenciando que a substituição entre planos coletivos e individuais estaria prejudicada por diferenças: $i$ ) no cálculo do risco; ii) no grau de regulação incidente; iii) na assimetria da substituição; e iv) no valor dos prêmios.

Entendemos que o cálculo do risco e o grau de regulação incidente afetam tão somente as condutas das operadoras, sem ter relação direta com o locus do mercado relevante (geográfico ou produto), uma vez que o consumidor pode desconhecer essas distinções e ignorá-las no seu processo de escolha. A assimetria da substituição, como bem aponta Santos (2008), serve mais para subdividir o segmento de planos coletivos em empresarial e coletivo por adesão, dado que o usuário de um plano individual nem sempre pode substituí-lo por um coletivo, mas não é impossível tal substituição. Finalmente, o argumento sobre o valor dos prêmios carece de evidências para ser demonstrado. ${ }^{22}$ Nesse sentido, Duclos (2006) segmenta os planos apenas de acordo com a cobertura dos serviços, isto é, ambulatoriais versus hospitalares, versus mistos, versus odontológicos. Nesse debate, o Conselho Administrativo de Defesa Econômica (Cade) acabou aderindo, aparentemente, à segmentação proposta por Santos (2008) e a consagrou em sua jurisprudência.

Os planos coletivos apresentam ainda uma subdivisão entre planos por adesão e planos empresariais. Nos primeiros, a adesão é facultada a possíveis beneficiários que possuam vínculo com pessoas jurídicas de caráter profissional, classista ou setorial, como sindicatos, associações, conselhos profissionais etc. Nos últimos, podem ser beneficiárias pessoas vinculadas a uma pessoa jurídica através de relação empregatícia ou estatutária. A jurisprudência do Cade não considera essa diferença para fins de definição de mercado relevante, incluindo ambas as categorias em planos coletivos (DEE, 2018, p. 41).

De fato, segundo Ragazzo e Machado (2011), o Sistema Brasileiro de Defesa da Concorrência (SBDC) vinha adotando até então a seguinte classificação para definição dos mercados relevantes em seus pareceres e votos: $i$ ) plano médico individual/familiar; ii) plano médico coletivo; iii) plano exclusivamente odontológico individual/familiar e iv) plano exclusivamente odontológico coletivo.

\section{REFERÊNCIAS}

ANDRADE, M. V. et al. Mercados e concentração no setor suplementar de planos e seguros de saúde no Brasil. Pesquisa e Planejamento Econômico, v. 42, n. 3, p. 329-361, 2012.

ANS - AGÊNCIA NACIONAL DE SAÚDE SUPLEMENTAR. Relatório da Audiência Pública no 10: audiência pública sobre política de preços e reajustes na saúde suplementar. Rio de Janeiro: ANS, 2018. Disponível em: <https://bit. ly/3hknWe2>. Acesso em: 2 set. 2020.

22. É problemático usar diferenças de preços para definir mercados relevantes. Além da chamada falácia do celofane, que usa preços já monopolísticos ao se aplicar o teste do monopolista hipotético, existe a chamada falácia reversa do celofane, que ocorre justamente em mercados regulados: preços que podem ser artificialmente baixos causam a impressão de que outros produtos sejam substitutos mais fracos e, portanto, conduzir a definições de mercado relevante inapropriadamente estreitas e inferências errôneas de poder de mercado (Aron e Burnstein, 2010). 
ARON, D. J.; BURNSTEIN, D. E. Regulatory Policy and the reverse cellophane fallacy. Journal of Competition Law and Economics, v. 6, n. 4, p. 973-994, 2010.

DEE - DEPARTAMENTO DE ESTUDOS ECONÔMICOS. Atos de concentração nos mercados de planos de saúde, hospitais e medicina diagnóstica. Brasília: DEE, 2018.

DUCLOS, M. T. Atos de concentração, poder de monopsônio e restrições verticais no mercado de saúde suplementar. In: FIUZA, E. P. S.; MOTTA, R. S. (Orgs.). Métodos quantitativos em defesa da concorrência e regulação econômica. Rio de Janeiro: Ipea, 2006.

RAGAZZO, C. E. J.; MACHADO, K. Desafios da análise do CADE no setor de planos de saúde. São Paulo: LCTE, 2011. Disponível em: <https://bit.ly/2FMpfo9>. Acesso em: 20 fev. 2019.

SANTOS, T. Determinação de mercados relevantes no setor de saúde suplementar. Brasília: Seae/MF, 2008. (Documento de Trabalho, n. 46). 


\section{APÊNDICE B}

\section{Indicador ou medida de eficiência}

Um indicador ou medida de eficiência não pode ser qualquer medida matemática ou estatística, por mais conhecida que seja. Nem todos os tipos de indicadores úteis para avaliar o desempenho de uma unidade produtiva são indicadores de eficiência. O conceito de eficiência de Pareto-Koopmans, que já descrevemos, é muito útil, muito utilizado por economistas, mas é bastante restritivo. Outros conceitos também podem ser válidos. Entretanto, para que um conceito origine uma medida de eficiência razoável, algumas características mínimas devem ser observadas.

Vejamos as propriedades de uma boa medida de eficiência, conforme descritas em Bogetoft e Otto (2011). Nesse contexto, faremos breves considerações, que julgamos importantes e que não são contempladas liminarmente pelo novo indicador da Agência Nacional de Saúde Suplementar (ANS), não relaciona um número real a um conjunto formado por outputs que foram produzidos por determinados inputs, ficando, portanto, aquém da Teoria da Produção e da Firma, apresentada em compêndios de microeconomia.

Os conceitos são retratados a seguir.

1) Flexibilidade: para ter interesse geral, um conceito de eficiência deve ser aplicável a uma ampla classe de tecnologias. Não é razoável que se elabore uma medida de eficiência para cada problema particular. O melhor guia para evitar esse problema é a literatura científica sobre o assunto.

2) Métrica: uma medida de eficiência, basicamente, mapeia um plano de produção e uma tecnologia no conjunto dos números reais. Isso significa que a medida de eficiência deve ser, em princípio, um número real. Normalmente, um escore de eficiência é apresentado como um número puro ou um percentual. Também é aconselhável trabalhar com escores no intervalo $[0,1]$ ou $[0,100 \%]$. Nesse intervalo, uma unidade produtiva com eficiência igual a unidade ou $100 \%$ é dita eficiente, e, quanto maior o escore, maior será a eficiência e vice-versa.

3) Comensurabilidade ou invariância para permutações e reescalonamento: não importa a ordem de apresentação de inputs e de outputs. Também não interessa se reescalonamos todos os diferentes inputs e outputs. Por exemplo, não importa se medimos inputs e outputs em reais ou em dólares, em dias ou meses de internação, desde que eles sejam medidos nas mesmas unidades em todas as unidades produtivas. Assim, não é possível medir a receita de uma operadora de plano de saúde em dólares e compará-la com a receita de outra operadora medida em reais.

4) Indicação: somente os pontos eficientes sob Pareto-Koopmans são plenamente eficientes. Trata-se de uma propriedade mais técnica, mas cuja desconsideração pode acarretar sérias consequências na avaliação. Se um modelo não computa as folgas (trechos horizontais ou verticais) nas isoquantas, ${ }^{23}$ pode-se não perceber totalmente a possibilidade de economia de inputs ou de expansão de outputs. Isso ocorreria porque a medida de eficiência adotada no referido modelo é apenas radial, ou seja, considera apenas a possibilidade de aumento equiproporcional em outputs, ou redução equiproporcional em inputs, mas não considera as folgas isoladas em alguns dos outputs ou os excessos isolados em alguns dos inputs.

5) Homogeneidade de grau 1: se multiplicamos os inputs por uma constante positiva, dividimos a eficiência pela mesma constante. Se multiplicarmos os outputs por uma mesma constante positiva, a eficiência fica multiplicada pela mesma constante. Aqui não estamos falando de retornos de escala. Não estamos avaliando o efeito nos outputs, da multiplicação ou divisão dos inputs por uma constante. Estamos falando no efeito sobre os próprios escores de eficiência. Então, se uma operadora de plano de saúde tem eficiência igual a $100 \%$, e dobramos o seu uso de inputs, mantido o nível de outputs, a sua eficiência deverá será agora de $50 \%$.

6) Monotonicidade: se aumentamos o consumo de pelo menos um input, sem aumento da produção de algum output, reduzimos a eficiência e vice-versa. Fenômeno similar ocorre se reduzimos a produção de algum output sem a redução de algum input e vice-versa.

7) Continuidade: se variarmos em pequena monta o consumo de inputs, ou a produção de outputs, o escore de eficiência deve variar continuamente (sem grandes saltos). A medida de eficiência não deve ter sensibilidade extrema, pois não desejamos que pequenos erros ou imprecisões nos dados tenham impactos exacerbados sobre a eficiência.

\footnotetext{
23. Uma isoquanta pode ser definida como o conjunto dos pontos que representam combinações de insumos que produzem o mesmo nível de produção. A isoquanta é uma referência para a unidade produtiva (que pode ser uma operadora de planos de saúde ou um hospital etc.), porque indica quais a combinações de cestas de insumos que produzem um determinado nível fixo de produção. Assim, se a firma, para produzir um determinado nível de produto, usar mais insumos do que está indicado pela isoquanta da qual esse nível de produto faz parte, ela não é "tecnicamente" eficiente.
} 
Bogetoft e Otto (2011) também abordam aspectos aplicados a serem considerados na escolha entre as medidas de eficiência possíveis.

1) Controlabilidade: são importantes os inputs e outputs que são controlados pelas unidades tomadoras de decisão (decision making units - DMUs) que estão sendo avaliadas, pois não se pode extrair informação ou incentivar as DMUs com base em variáveis fora de seu controle. Isso significa, em particular, que não são úteis informações sobre eficiência orientada a insumos, se a quantidade desses insumos está dada para a DMU, e este se aplica aos outputs. Claro que a flexibilidade do fator de produção depende do horizonte de tempo em tela, pois, no longo prazo, mais fatores de produção são variáveis.

2) O uso pretendido do escore de eficiência é crucial. Para uma experiência de aprendizado, a medida exata de eficiência é menos importante que a capacidade de encontrar pares relevantes levando em conta as preferências, estratégias etc. das próprias firmas. Em uma aplicação de alocação, a distinção entre inputs fixos e variáveis é normalmente importante. Em uma aplicação de incentivos, a tarefa é encontrar uma agregação de desempenhos que permita a contratação ótima.

3) A facilidade de interpretação.

4) A disponibilidade de dados. Por exemplo, disponibilidade de preços de insumos permite a realização de análises de eficiência de custos, que decompõe a eficiência em alocativa e técnica. A disponibilidade de dados longitudinais permite distinguir entre efeitos horizontais/transversais de tendência geral de produtividade e efeitos de catching up.

5) A facilidade de computação.

\section{REFERÊNCIA}

BOGETOFT, P.; OTTO, L. Benchmarking with DEA, SFA and R. New York: Springer, 2011. 
Ipea - Instituto de Pesquisa Econômica Aplicada

\section{EDITORIAL}

\section{Coordenaçãa}

Reginaldo da Silva Domingos

\section{Assistente de Coordenação}

Rafael Augusto Ferreira Cardoso

\section{Supervisão}

Camilla de Miranda Mariath Gomes

Everson da Silva Moura

\section{Revisão}

Amanda Ramos Marques

Ana Clara Escórcio Xavier

Clícia Silveira Rodrigues

Idalina Barbara de Castro

Luiz Gustavo Campos de Araújo Souza

Olavo Mesquita de Carvalho

Regina Marta de Aguiar

Hellen Pereira de Oliveira Fonseca (estagiária)

Ingrid Verena Sampaio Cerqueira Sodré (estagiária)

\section{Editoração}

Aeromilson Trajano de Mesquita

Cristiano Ferreira de Araújo

Danilo Leite de Macedo Tavares

Herllyson da Silva Souza

Jeovah Herculano Szervinsk Junior

Leonardo Hideki Higa

\section{Capa}

Danielle de Oliveira Ayres

Flaviane Dias de Sant'ana

\section{Projeto Gráfico}

Renato Rodrigues Bueno

The manuscripts in languages other than Portuguese published herein have not been proofread.

\section{Livraria Ipea}

SBS - Quadra 1 - Bloco J - Ed. BNDES, Térreo

70076-900 - Brasília - DF

Tel.: (61) 2026-5336

Correio eletrônico: livraria@ipea.gov.br 

Composto em linux libertine 10/13 (texto) 



\section{Missão do Ipea}

Aprimorar as políticas públicas essenciais ao desenvolvimento brasileiro por meio da produção e disseminação de conhecimentos e da assessoria ao Estado nas suas decisões estratégicas.

\section{ipea Econômica Aplicada}

